\title{
Maximum Energy Efficiency Tracking for Wireless Power Transfer Systems
}

\author{
Wenxing Zhong, Member, IEEE and S.Y.R Hui, Fellow, IEEE
}

\begin{abstract}
A method for automatic "maximum energy efficiency tracking" (MEET) operation for wireless power transfer systems is presented in this paper. Using the switched mode converter in the receiver module to emulate the optimal load value, the proposed method follows the maximum energy efficiency operating points of a wireless power transfer system by searching for the minimum input power operating point for a given output power. Because the searching process is carried out on the transmitter side, the proposal does not require any wireless communication feedback. The control scheme has been successfully demonstrated in a 2-coil system under both weak and strong magnetic coupling conditions. Experimental results are included to confirm its feasibility.
\end{abstract}

Index Terms - Wireless power transfer, maximum energy efficiency tracking

\section{INTRODUCTION}

$\mathrm{T}$ HE availability of modern power electronics with fast switching speeds and high power handing capability has offered the necessary technology to revive the interests in wireless power transfer in early 1990's [1][2] when the power electronics based inductive power transfer technology was investigated for inductive power pickup systems [3][4]. The dawn of the mobile phone era in the mid 1990's is another factor [5] that further intensifies research activities in planar wireless power systems for portable consumer electronics. By early 2000's, various forms of planar wireless charging systems have emerged [6]-[9]. With the formation of the Wireless Power Consortium in 2008 (now comprising over 210 companies worldwide in over 16 countries), and the launched of the wireless power standard "Qi" [10], it has been reported [11] that over 500 products have been certified as Qi-compatible by 2014. Recent intense research activities in wireless power transfer have extended to stationary and dynamic wireless charging of electric vehicles and trains [12]-[18]. In a critical review [19], it has been pointed out that the use of "maximum energy efficiency" principle is more appropriate that "maximum power transfer" principle based on the impedance matching of the source impedance. However,

Manuscript received May 21, 2014; revised July 22, 2014; accepted August 17, 2014.This work was supported by the Hong Kong Research Grant Council under Grant GRF HKU 712913.

W. Zhong is with the Department of Electrical \& Electronic Engineering, The University of Hong Kong (e-mail: wenxingzhong@ gmail.com).

S.Y.R. Hui is with the Department of Electrical \& Electronic Engineering, The University of Hong Kong (e-mail: ronhui@eee.hku.hk) and also with Imperial College London (e-mail: r.hui@imperial.ac.uk). the maximum energy efficiency operating point is dynamically changing with the load conditions [20], the coupling coefficient and quality factor [23][24]. Therefore, there is a need for developing new technology to track the maximum energy efficiency operating point. For solar power applications, maximum power point tracking (MPPT) is a well-known concept. But for wireless power transfer applications, the load-dependent energy efficiency suggests that it is appropriate to tracking the maximum efficiency operating point for a dynamically changing load. So far, variations of the energy efficiency have been addressed in wireless power domino systems [20] and 3kW electric vehicle charging systems [23]. In [24], a compensating scheme has been proposed to select the operating frequency in order achieve high energy efficiency and good voltage controllability for a wide range of load conditions. Such high energy efficiency is in the context of the top region (say 10\%) of the maximum energy efficiency range. In this paper, a method for maximum energy efficiency tracking (MEET) is explored and evaluated. Using the switched mode converter in the receiver module to emulate the optimal equivalent load condition dynamically, the proposed method ensures automatic MEET by searching for the minimum input power operating point for a given output power [21][22]. The operating principle is demonstrated in a 2-coil wireless power transfer system designed to operate at the maximum energy efficiency principle. Experimental results are included to confirm the feasibility of the proposal.

\section{OPTIMAL LOAD CONDITIONS FOR MAXIMUM ENERGY EFFICIENCY AND MAXIMUM POWER OPERATIONS}

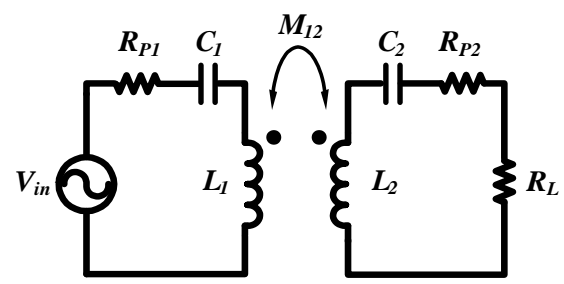

Fig. 1. Circuit model of a two-coil WPT system.

Consider a simple 2-coil wireless power transfer (WPT) system with its equivalent circuit shown in Fig.1. Assuming that the power losses in the ferrite plates that shield the transmitter and receiver coils are negligible, the coupled circuit equations for the system are 


$$
\begin{aligned}
& \left(R_{P 1}+j X_{1}\right) \mathbf{I}_{1}+j \omega M_{12} \mathbf{I}_{2}=\mathbf{V}_{i n} \\
& j \omega M_{12} \mathbf{I}_{1}+\left(R_{P 2}+R_{L}+j X_{2}\right) \mathbf{I}_{2}=\mathbf{0}
\end{aligned}
$$

where $\omega$ is the angular frequency of the operation; $X_{i}(i=1,2)$ is the reactance $\omega L_{i}-1 /\left(\omega C_{i}\right)$ of Resonator $-i ; \mathbf{I}_{1}$ and $\mathbf{I}_{2}$ are the current vectors of the Resonator- 1 and Resonant- 2 respectively; $R_{P 1}$ and $R_{P 2}$ are the winding resistance of Resonant- 1 and Resonant-2, respectively; $C_{1}$ and $C_{2}$ are the resonant capacitors of Resonant-1 and Resonant-2, respectively; $R_{L}$ is the load resistance.

\section{A. Optimum Load for Maximum Energy Efficiency Operation}

Assuming the core losses in the magnetic ferrite plates and the power inverter losses are negligible, the energy efficiency $(\eta)$ of a 2-coil wireless power transfer system can then be expressed as:

$$
\eta=\frac{I_{2}^{2} R_{L}}{I_{1}^{2} R_{P 1}+I_{2}^{2}\left(R_{P 2}+R_{L}\right)}=\frac{R_{L}}{\left(\frac{I_{1}}{I_{2}}\right)^{2} R_{P 1}+R_{P 2}+R_{L}}
$$

The ratio of the root-mean-square currents $I_{1} / I_{2}$ can be obtained by solving (2) without using (1). In other words, the compensating condition in Resonator-1 (or the value of $X_{1}$ ) will not affect the efficiency of the system. With (2), the energy efficiency can be further determined as

$$
\eta=\frac{\omega^{2} M_{12}^{2} R_{L}}{\left[\left(R_{P 2}+R_{L}\right)^{2}+X_{2}^{2}\right] R_{P 1}+\omega^{2} M_{12}^{2}\left(R_{P 2}+R_{L}\right)}
$$

If the operating frequency $f(\omega=2 \pi f)$ is chosen, the maximum energy efficiency (MEE) conditions can be determined by the following procedure. Firstly, by differentiating $\eta$ with respect to $X_{2}$ and equating the differential function to zero,

$$
\frac{\partial \eta}{\partial X_{2}}=0
$$

the optimum value of $X_{2}$ for maximum efficiency can be obtained as

$$
X_{2_{-} O P T_{-} \eta}=0
$$

Then by differentiating $\eta$ with respect to $R_{L}$ and equating the differential function to zero,

$$
\frac{\partial \eta}{\partial R_{L}}=0
$$

the optimum value of $R_{L}$ for maximum efficiency can be obtained as

$$
R_{L_{-} O P T_{-} \eta}=\sqrt{R_{P 2}^{2}+X_{2}^{2}+\omega^{2} M_{12}^{2} R_{P 2} / R_{P 1}}
$$

If $X_{2}=X_{2} O P T_{-} \eta=0$, then the optimal load for maximum energy efficiency is [20]:

$$
R_{L_{-} O P T_{-} \eta}=R_{P 2}\left(\sqrt{1+\frac{\omega^{2} M_{12}^{2}}{R_{P 1} R_{P 2}}}\right)
$$

\section{B. Optimum Load for Maximum Power Operation}

The output power of the system is

$P_{O}=I_{2}^{2} R_{L}$

$$
=\frac{\omega^{2} M_{12}^{2} V_{i n}^{2} R_{L}}{\left(\omega^{2} M_{12}^{2}+R_{P 1} R_{P 2}+R_{P 1} R_{L}-X_{1} X_{2}\right)^{2}+\left(R_{P 1} X_{2}+R_{P 2} X_{1}+R_{L} X_{1}\right)^{2}}
$$

By solving

$$
\frac{\partial P_{O}}{\partial R_{L}}=0
$$

the optimal load for maximum power transfer can be determined as:

$$
R_{L_{-} O P T_{-} P o}=\sqrt{\frac{\left(\omega^{2} M_{12}^{2}+R_{P 1} R_{P 2}-X_{1} X_{2}\right)^{2}+\left(R_{P 1} X_{2}+R_{P 2} X_{1}\right)^{2}}{R_{P 1}^{2}+X_{1}^{2}}}
$$

When the system is operated at the resonant frequency of the receiver resonator $\left(X_{2}=0\right)$ so that the maximum efficiency of the system can be achieved, equation (12) can be rewritten as $P_{O}=\frac{\omega^{2} M_{12}^{2} V_{i n}^{2} R_{L}}{\left(\omega^{2} M_{12}^{2}+R_{P 1} R_{P 2}+R_{P 1} R_{L}\right)^{2}+\left(R_{P 2} X_{1}+R_{L} X_{1}\right)^{2}}$

therefore

$$
X_{1 \_O P T_{-} P o}=0
$$

and the expression in (12) can now be simplified as:

$$
R_{L_{-} O P T_{-} P o}=R_{P 2}\left(1+\frac{\omega^{2} M_{12}^{2}}{R_{P 1} R_{P 2}}\right)
$$

\section{C.Comparison of optimal load conditions}

$\begin{array}{lll}\text { From (7) and } & \text { (13), it can be seen that }\end{array}$ the optimal load conditions for maximum energy efficiency operation and maximum power transfer operation are different. The bracketed term in (9) is $\sqrt{1+\frac{\omega^{2} M_{12}^{2}}{R_{P 1} R_{P 2}}}$. The bracketed term in (15) is $\left(1+\frac{\omega^{2} M_{12}^{2}}{R_{P 1} R_{P 2}}\right)$. In addition, since the bracket term in (15) is greater than 1 , comparing (9) and (15) leads to the following inequality:

$$
R_{L_{-} O P T_{-} \eta}<R_{L_{-} O P T_{-} P O}
$$

In the proposed MEET method for, it is the optimal load resistance $R_{L_{-} O P T_{-} \eta}$ in (9) that is adopted. 


\section{NEW CONTROL METHOD FOR MAXIMUM ENERGY EFFICIENCY TRACKING (MEET)}

The MEET concept is now explained with the aid of the circuit structure in Fig.2 and a mapping diagram in Fig.3. Although this explanation is based on a two-stage output power circuit, i.e. using a front-end AC-DC power converter followed by a DC-DC power converter, the idea applies to a single-stage AC-DC power converter. The ac input voltage $v_{\text {in }}$ on the transmitter side is the output voltage provided by a power inverter. Because a resonator is used as the transmitter, the fundamental component at the resonant frequency is the only dominant voltage component. The source impedance of this transmitter circuit is therefore very small, making it possible for high energy efficiency for the entire system.

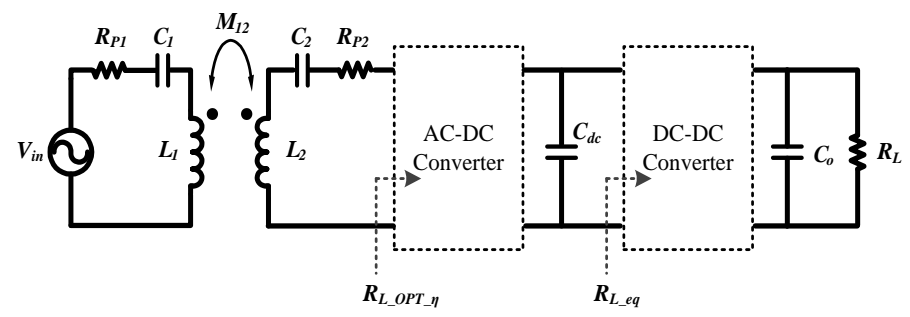

Fig. 2. Schematic of a two-winding WPT system with AC-DC and DC-DC converters.

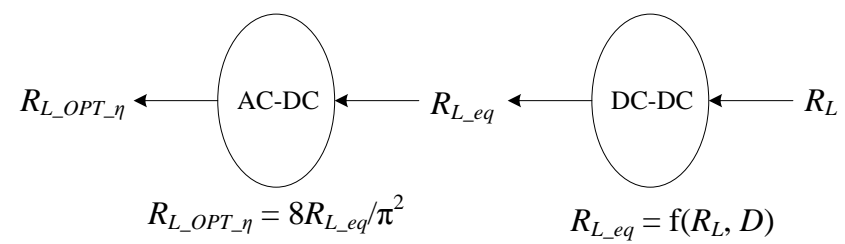

Fig. 3. Load resistance transformation process.

In practice, the actual load $R_{L}$ may vary with time. For a given WPT system, MEET can be achieved by adjusting the equivalent resistance of the load circuit (comprising the AC-DC and DC-DC power conversion either in single-stage or 2-stage arrangement) to meet the optimal load condition of (9). In order to adjust the equivalent resistance to the optimal load value for achieving MEET, the duty-cycle control of power converter can be used. In the two-stage example of Fig.3, the relationship between the input resistance of the receiver circuit and load depending on the relationship of the input resistance and the equivalent resistance in the intermediate stage $R_{L_{-} e q}=$ $\mathrm{f}\left(R_{L}, D\right)$, which is a function of the output load $R_{L}$ and the duty-cycle $D$ of the DC-DC converter.

The function in Fig. 3 depends on the type of the DC-DC converters used. For example for buck-boost converter, the voltage ratio is

$$
\frac{V_{\text {out }}}{V_{\text {in }}}=-\frac{D}{1-D}
$$

and the output power equals to the input power under steady state operation,

$$
V_{\text {in }} I_{\text {in }}=V_{\text {out }} I_{\text {out }}
$$

therefore, by using (17) and (18), we can get

$$
R_{L_{-} e q}=\frac{V_{\text {in }}}{I_{\text {in }}}=\left(\frac{V_{\text {in }}}{V_{\text {out }}}\right)^{2} R_{L}=\left(\frac{1-D}{D}\right)^{2} R_{L}
$$

Similarly the relationships between the equivalent resistance seen into the DC-DC converter and the load resistance can be obtained for any type of DC-DC converters.

For buck converter,

$$
R_{L_{-} e q}=\left(\frac{1}{D}\right)^{2} R_{L}
$$

For boost converter,

$$
R_{L_{-} e q}=(1-D)^{2} R_{L}
$$

For SEPIC converter

$$
R_{L_{-} e q}=\left(\frac{1-D}{D}\right)^{2} R_{L}
$$

For Cuk converter

$$
R_{L_{-} e q}=\left(\frac{1-D}{D}\right)^{2} R_{L}
$$

In general, regardless of using a single-stage or a 2-stage power converter in the receiver circuit, the objective of the control is to vary the duty cycle of the power converter so that the input equivalent resistance of the receiver circuit and (time-varying) load can be adjusted to the optimal value specified in equation (9). This control could be realized through two approaches, i.e.:

- Approach A - Direct control at the optimal duty cycle based on load sensing;

- Approach B - Determination of the optimal duty cycle based on a searching process.

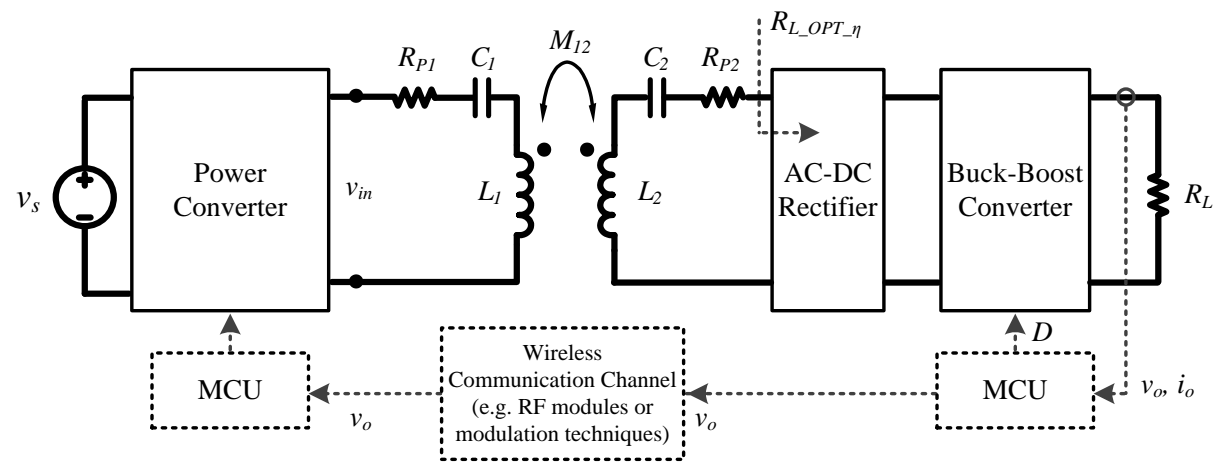

Fig. 4. An example of Approach A. 


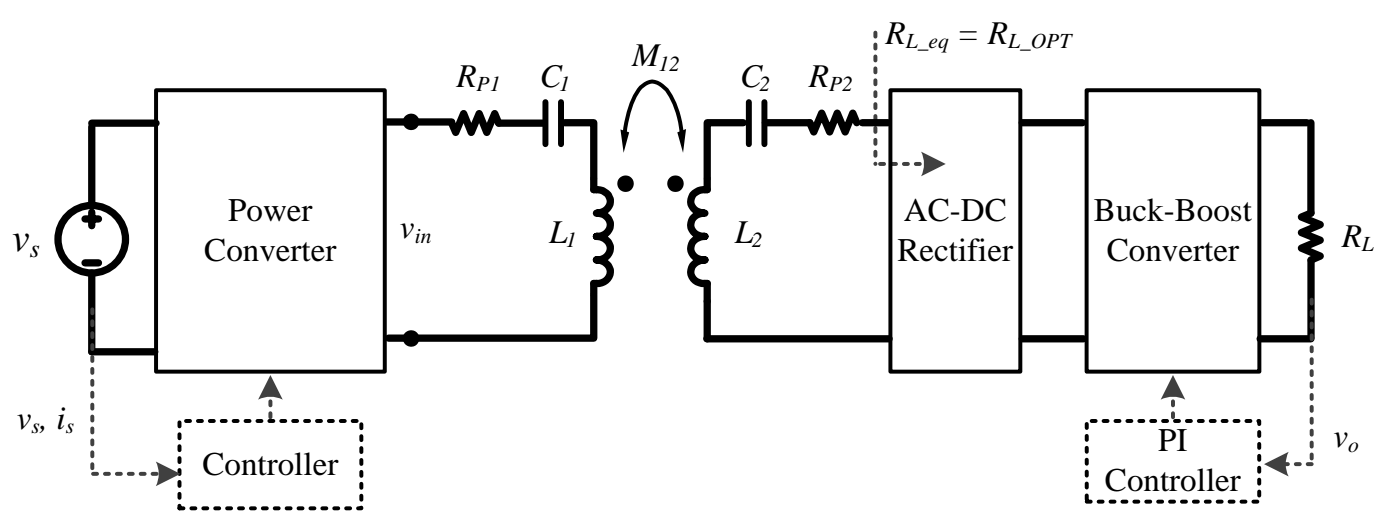

Fig. 5. Schematic of a two-winding WPT system with AC-DC and DC-DC converters.

For Approach A, the optimal duty cycle of the converter is decided by sensing the load resistance. The output voltage of the system is regulated by sensing the output voltage and feeding the signal back to the transmitter side to adjust the input voltage $v_{i n}$. Therefore, a wireless communication channel is required. An example is shown in Fig. 4.

While Approach B is more sophisticated, it does not need a wireless communication between the transmitter and receiver. Therefore, it is more cost-effective for practical implementations and the rest of this paper will focus on Approach B.

\section{SEARChING FOR THE OPTIMAL DUTy CYCLE FOR MEET}

In this approach, a DC-DC converter is used to regulate the output in order to maintain a constant output voltage, as shown in Fig. 5. The transmitter power circuit initially provides an input voltage of a sufficiently high value to drive the transmitter coil. Such input voltage $v_{\text {in }}$ of the primary resonator is then adjusted (i.e. decreased or increased) iteratively until the input power of the transmitter circuit reaches a minimum point. For a given output power, reaching a minimum input power operating point means is equivalent to reaching the maximum energy efficiency operating point.

Because the switching frequency of the DC-DC power converter is typically in the order of tens of hundreds of kilo-Hertz, the control action of the power converter can be much faster than the variation of the load impedance. In this iterative searching process for the maximum energy efficiency point, the load resistance can be assumed to be constant and the duty cycle of the DC-DC converter will be forced to alter accordingly in order to maintain a constant output voltage which means the output power is constant. Therefore, when a minimum input power point is found, it is also a maximum efficiency point and the DC-DC converter operating at this point is transforming the load resistance to the optimum value, or in other words, (9) has been realized through this searching process.

The flow chart of this approach is shown in Fig. 6 and described as follows. It is reasonable in any good design that the power rating of the power supply must be sufficient for the maximum load power for a particular application.

1. An initial input $\mathrm{AC}$ voltage $V_{i n 0}$ on the transmitter coil is applied. This voltage should preferably be high enough for delivering enough power to a targeted load on the receiver side for a designated output voltage under all possible operating conditions.

2. The DC-DC converter on the receiver side automatically adjusts its duty cycle to generate the designated output voltage for a given load. This initial duty cycle is denoted $D_{0}$.

3. The input power $P_{i n 0}$ to the transmitter coil is measured and recorded by the control unit on the primary side.

4. The input $\mathrm{AC}$ voltage $V_{\text {in }}$ is then increased (or decreased) slightly (e.g. $\Delta V_{\text {in }}=5 \% V_{\text {in } 0}$ ) to a new value $V_{i n 1}=V_{i n 0}+\Delta V_{\text {in }}$ (or $\left.V_{i n 1}=V_{i n 0}-\Delta V_{i n}\right)$. Changing the input ac voltage to the transmitter coil on the primary side will change the input DC voltage of the DC-DC converter on the receiver side.

5. Once again, the DC-DC converter will be forced to regulate its duty cycle in order to regulate the output voltage. Now the duty cycle is denoted as $D_{l}$.

6. The input power $P_{\text {inl }}$ to the Transmitter coil is measured and recorded.

7. Compare $P_{i n 1}$ and $P_{i n 0}$. If $P_{i n 1}$ is smaller than $P_{i n 0}$ (which means the energy efficiency of the system rises), then repeat step 4 and 5 until the input power stops decreasing. Then a minimum input power point or a maximum efficiency point is found. Otherwise, if $P_{i n l}$ is larger than $P_{i n 0}$ (which means the energy efficiency of the system decreases), then the searching direction is reversed (i.e. apply $V_{i n l}=V_{i n 0}-\Delta V_{i n}$ ). Similarly, repeat step 4 and 5 until the input power stops decreasing and a maximum efficiency point is found.

8. The optimum operation point will be kept for a designated time interval, say $t_{d}$.

9. After this time interval $t_{d}$, a new searching process will start from this selected operating point in case that the load and/or the coupling $M_{12}$ have varied.

The major difficulty in realizing the proposed system is to design the control for the DC-DC converter so that not only a steady operating point can be found for a given input voltage but also the maximum energy efficiency point can be successfully found by searching from the initial steady operating point. Details and explanations are provided in the following design example. 


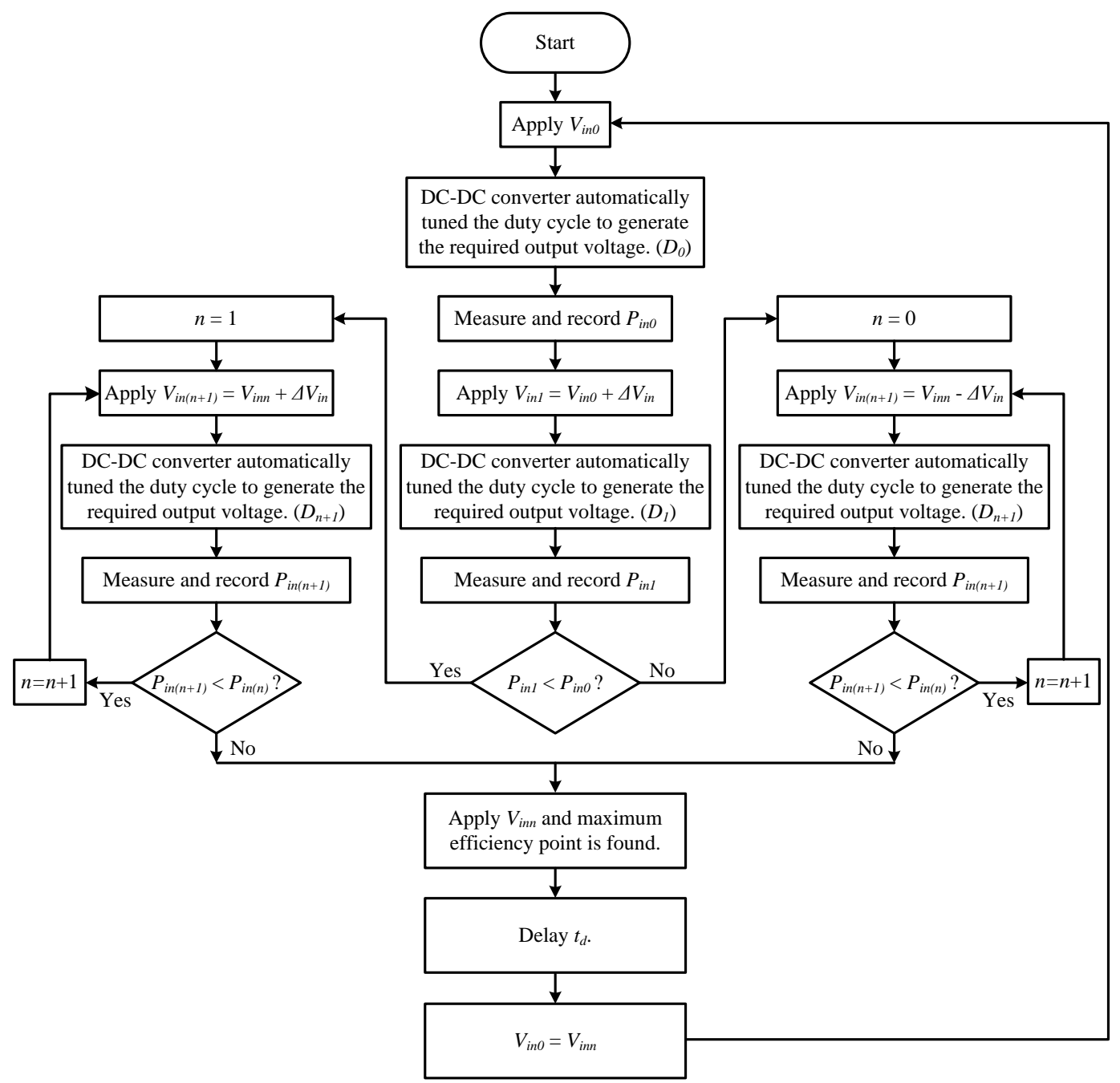

Fig. 6. Flow chart of the proposed control method.

\section{Design Example of Approach B}

The design example is based on a WPT system with two coil-resonators consisting with two coils with the same structure as shown in Fig. 7 and Fig. 8. For the first case study, the parameters of the system are specified in TABLE I. The operating frequency of the power inverter in the transmitter circuit is set at $100 \mathrm{kHz}$ which is approximately equal to the resonant frequencies of two resonators. The litz wire has 24 strands of no. $40 \mathrm{AWG}(0.08 \mathrm{~mm}$ diameter $)$ and a ferrite plate with a thickness of $1 \mathrm{~mm}$ is used for shielding the WPT system.

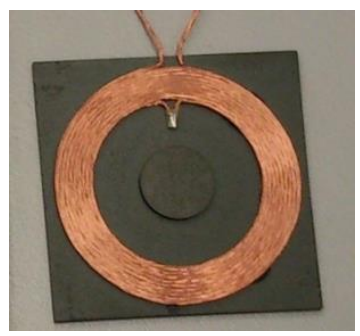

Fig. 7. The coil of a practical WPT system.

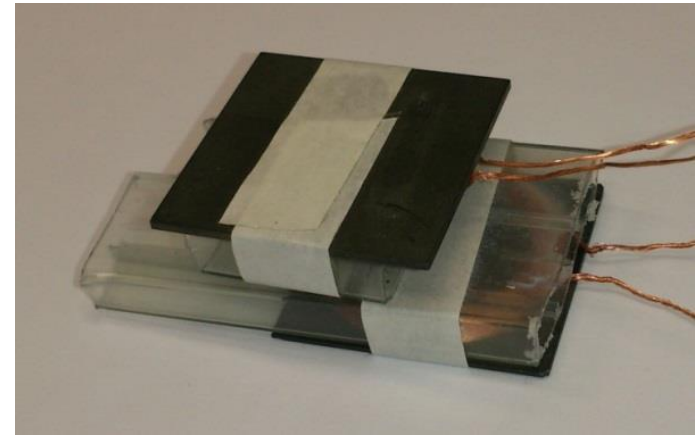

Fig. 8. A WPT system with a coupling coefficient of about 0.1. [Misalignment is considered purposely in order to emulate a weak magnetic coupling.]

In this first case study of weak coupling, the desired output voltage of the system is $2.5 \mathrm{~V}$ and the rated output power is $2.5 \mathrm{~W}$. Therefore, the load resistance can vary in the range from $2.5 \Omega$ to $+\infty$. A buck-boost converter is used in the output DC-DC stage in this example. Therefore, the relationship between the input resistance $R_{L_{-} e q}$ of the converter and the load resistance $R_{L}$ is given by (11).

\section{TABLE I}

PARAMETERS OF THE PRACTICAL WPT SYSTEM WITH A WEAK COUPLING 


\begin{tabular}{|c|c|c|}
\hline Parameters & Symbol & Practical Value \\
\hline Inner diameter & $d_{i}$ & $21.7 \mathrm{~mm}$ \\
\hline Coil width & $W_{r}$ & $5.32 \mathrm{~mm}$ \\
\hline Outer diameter & $d_{o}$ & $27.02 \mathrm{~mm}$ \\
\hline $\begin{array}{c}\text { Number of turns per } \\
\text { layer }\end{array}$ & - & 9 \\
\hline $\begin{array}{c}\text { Number of layers } \\
\text { Self-inductance of the } \\
\text { transmitter }\end{array}$ & $L_{l}$ & $23.2 \mu \mathrm{H}$ \\
\hline $\begin{array}{c}\text { Self-inductance of the } \\
\text { receiver }\end{array}$ & $L_{2}$ & $24.0 \mu \mathrm{H}$ \\
\hline $\begin{array}{c}\text { Mutual inductance } \\
\text { Compensating } \\
\text { capacitance of the } \\
\text { transmitter }\end{array}$ & $M_{l 2}$ & $2.56 \mu \mathrm{H}$ \\
\hline $\begin{array}{c}\text { Compensating } \\
\text { capacitance of the } \\
\text { receiver }\end{array}$ & $C_{l}$ & $106.2 \mathrm{nF}(\mathrm{Theoretical}$ \\
$109.2 \mathrm{nF})$
\end{tabular}

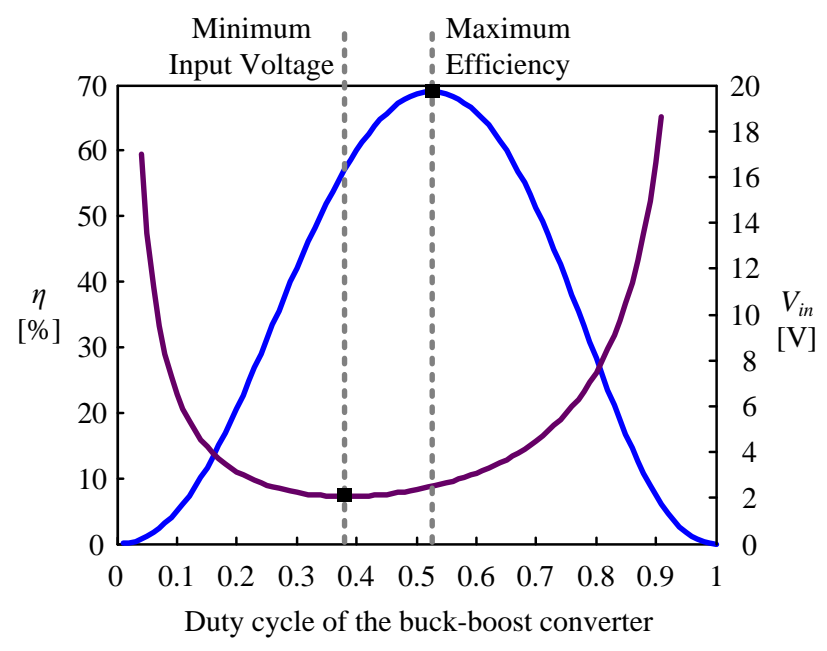

Fig. 9. Efficiency of the system and the required input voltage as $D$ varies.

For rated load resistance $R_{L}=2.5 \Omega$, the relationship between the duty cycle $D$ of the buck-boost converter and the efficiency of the system (assuming all the converters are lossless) and the input voltage of the primary resonator (i.e. the output voltage of the power inverter) is shown in Fig. 9. The searching process of the maximum energy efficiency operating point is now illustrated with the aid of Fig. 9. The purple solid line in Fig. 9 represents the required input voltage of the power inverter on the transmitter side in order to generate an output voltage of $2.5 \mathrm{~V}$ on the receiver side for a load resistance of 2.5 $\Omega$. At $D=0.38$, where is indicated with a vertical dotted line, input voltage required for an output power of $2.5 \mathrm{~W}$ in this example is at its minimum value. The dotted line separates the system operating range into two regions. The relationships between the duty cycle and the output voltage (or output power) are opposite in these two regions. On the left side $(D<0.38)$, the output power increases as $D$ increases (thereby a lower input voltage is required when $D$ becomes larger). On the right side $(D>0.38)$, the output power decreases as $D$ increases (thereby a higher input voltage is required when $D$ becomes larger). It is important to note that, only the region where the maximum energy efficiency operating point exists should be used for MEET operation. In this example, the region on the right side of the dotted line should be chosen as the operating region. If $10 \mathrm{~V}$ is used as the initial input voltage, the searching process based on Fig. 9 will allow the input voltage to change gradually to about $2.5 \mathrm{~V}$ at which the energy efficiency is at its maximum of $69 \%$. In Fig. 10, the efficiency is plotted against the input voltage of the primary resonator. One method to restrict the operation of the system within the right region is to restrict the duty cycle to be larger than 0.38 .

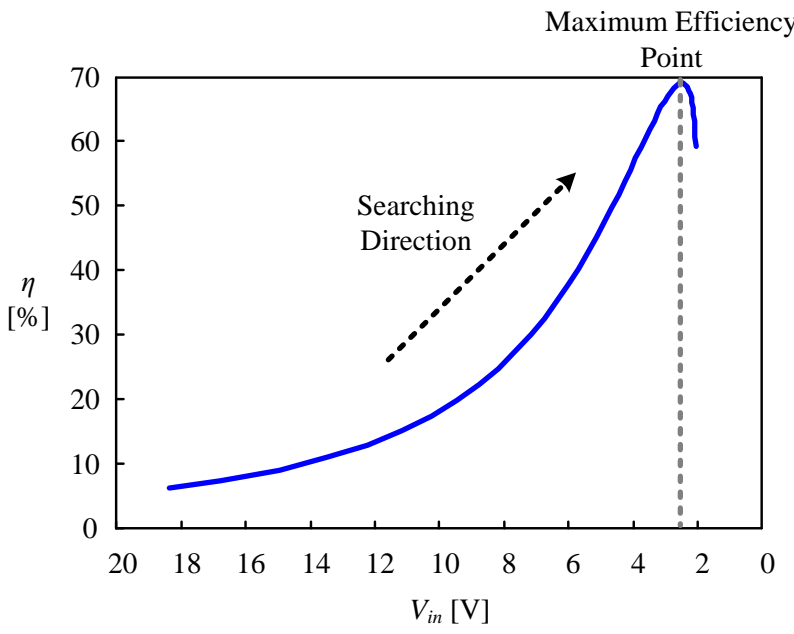

Fig. 10. Efficiency variation as the input voltage decrease and the duty cycle of the buck-boost converter is forced to search for a value to output the designated voltage.

However, on the right region of the dotted line in Fig. 9, the output DC voltage of the output converter (which is proportional to the power) increases as $D$ decreases. This output voltage and duty cycle relationship is opposite to the voltage gain characteristic of a standard buck-boost converter, i.e. equation (17) which indicates that the output voltage increases with increasing duty cycle. One method to implement the required control characteristics is to use the complement of the duty cycle, i.e. $D^{\prime}=1-D$ as shown in Fig. 11 . This can be practically achieved by using an inverter gate to invert the gate signal for the buck-boost converter. Instead of feeding $D$ to the gate drive as normally implies in Fig. 5, the complementary duty cycle $D^{\prime}$ is adopted in the gate drive control.

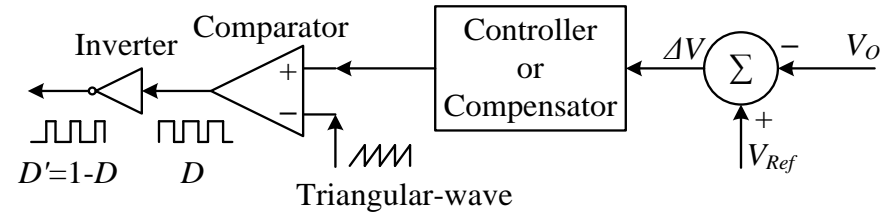

Fig. 11. Control loop for DC-DC converter operating on the right region.

Alternatively, a standard buck-boost converter could be used (without using the complement of the duty cycle) if one can adjust the minimum input voltage point to the left of the maximum efficiency point. This can be done by (i) tuning the 
operating frequency or (ii) tuning the natural resonant frequency of the transmitter by adjusting the value of the compensating capacitor $\left(C_{l}\right)$. However, for the first method (i), the maximum efficiency of the system will be degraded due to non-zero impedance $X_{2}$. For the second method (ii), the VA requirement of the power source increases due to non-zero $X_{1}$.

\section{EXPERIMENTAL VERIFICATIONS}

\section{A. Experiments with weak magnetic coupling}

For the case study based on parameters in Table I, experiments have been carried out to evaluate the performance of the 2-coil WPT system analyzed above. A full bridge power inverter is used in the transmitter circuit to generate a $100 \mathrm{kHz}$ AC supply for the transmitter coil. The DC input of the inverter is fixed at $5 \mathrm{~V}$. The output voltage of the inverter is adjusted by applying phase-shift control. For a load resistance of $2.5 \Omega$ and an output voltage of $2.5 \mathrm{~V}$, Fig. 12 and 13 show the output voltages of the inverter at the initial point and the optimum point, respectively. As observed in Fig. 13, the pulse width decreases from the original $5 \mu$ s to $2.26 \mu$ s when the optimum point is located. In Fig. 14, the source current (top trace) and the output voltage (bottom trace) of the system are shown. Since the source voltage is constant, the source current is proportional to the input power of the system. As indicated in Fig. 14, the source current reaches the minimum point at (1) [pulse width equals to $2.26 \mu \mathrm{s}$ ]; and the searching process continues [pulse width is decreased to $2.135 \mu \mathrm{s}$ ], the source current becomes larger at (2); then the duty cycle will be changed back to $2.26 \mu \mathrm{s}$ at (3). Normally, the searching process will stop at (3) because the optimum point has been found. However, in order to eliminate the errors due to noises, the searching process here is designed to search back one step to (4) where duty cycle is $2.385 \mu \mathrm{s}$. When it is confirmed by the controller that the source current at (4) is larger than the source current in (3), the control changes the duty cycle back to $2.26 \mu$ s at (5).

The measured efficiencies are compared with the simulation values obtained from PSpice circuit simulator. The slight difference between the experimental and simulation results arises from the fact that the power losses in the ferrite plates are not included and those of the power converters cannot be predicted precisely in the analysis. Taking this into account, the measured and simulated results agree well with each other. These results confirm that MEET can be achieved by adjusting the input voltage level and forcing the DC-DC converter at the receiver side to generate a constant output voltage. The results for a load of $5 \Omega$ are also obtained and illustrated in Fig. 16-18.

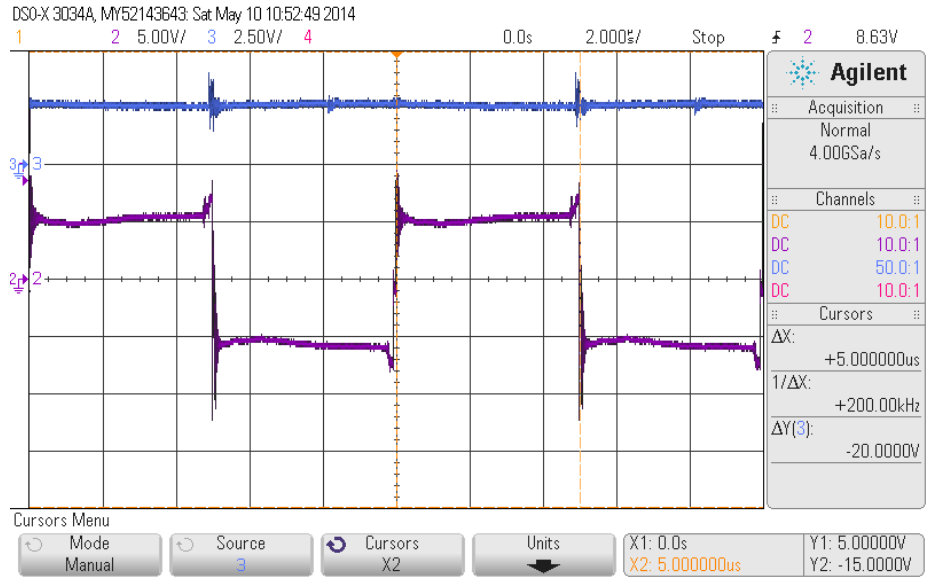

Fig. 12. The input voltage (bottom) of the primary coil and the output voltage (top) of the system at the initial point when $R_{L}=2.5 \Omega$.

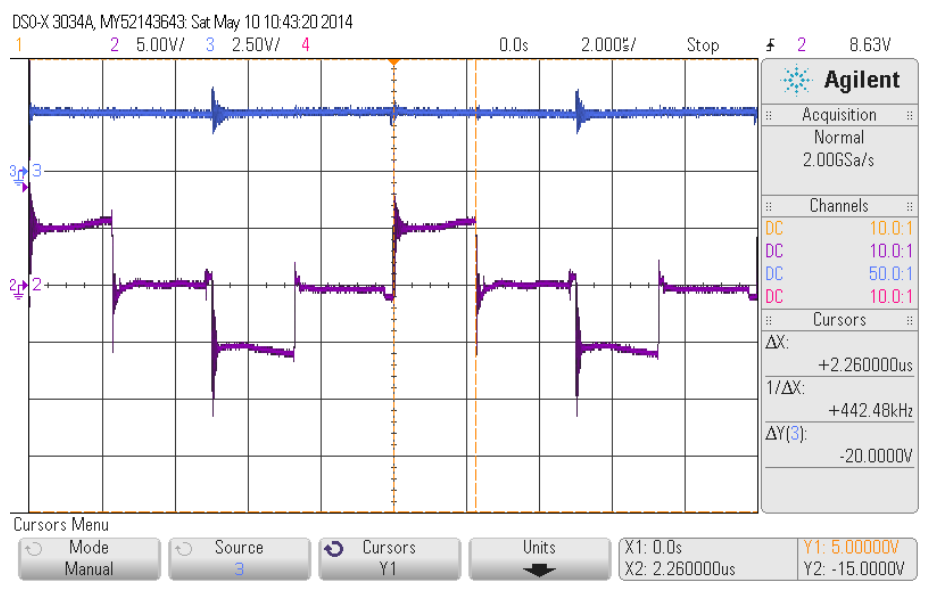

Fig. 13. The input voltage (bottom) of the primary coil and the output voltage (top) of the system at the optimum point when $R_{L}=2.5 \Omega$.

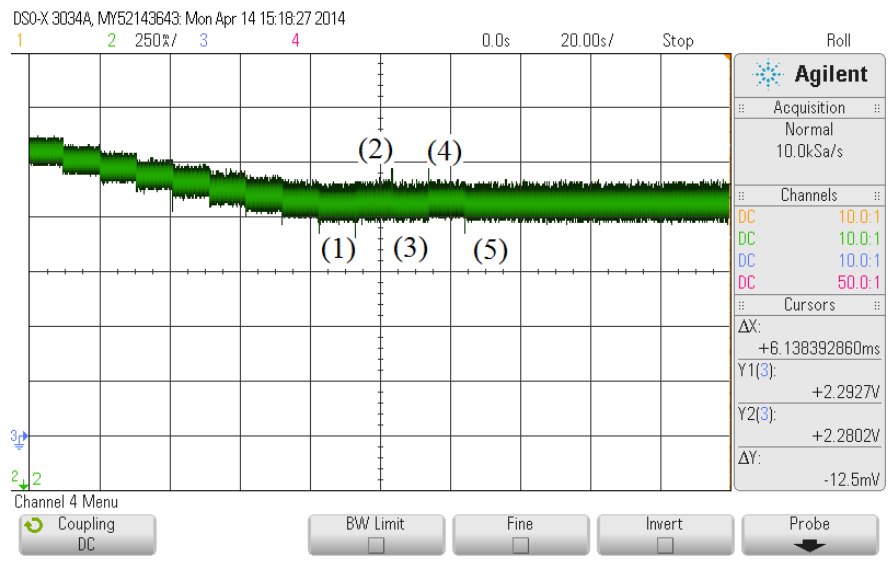

Fig. 14. The source current of the system. 


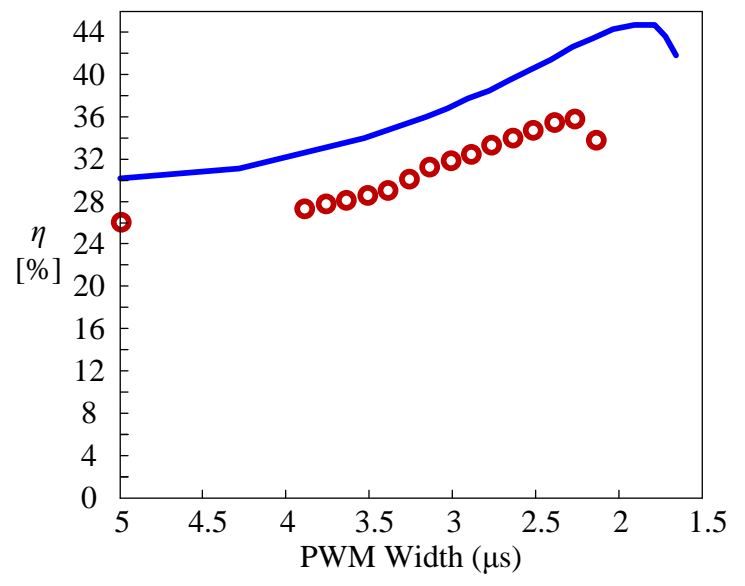

Fig. 15. Efficiency curves as a function of the pulse width of the output voltage of the inverter with $R_{L}=2.5 \Omega$ : top curve-simulation; bottom curve-measurement.

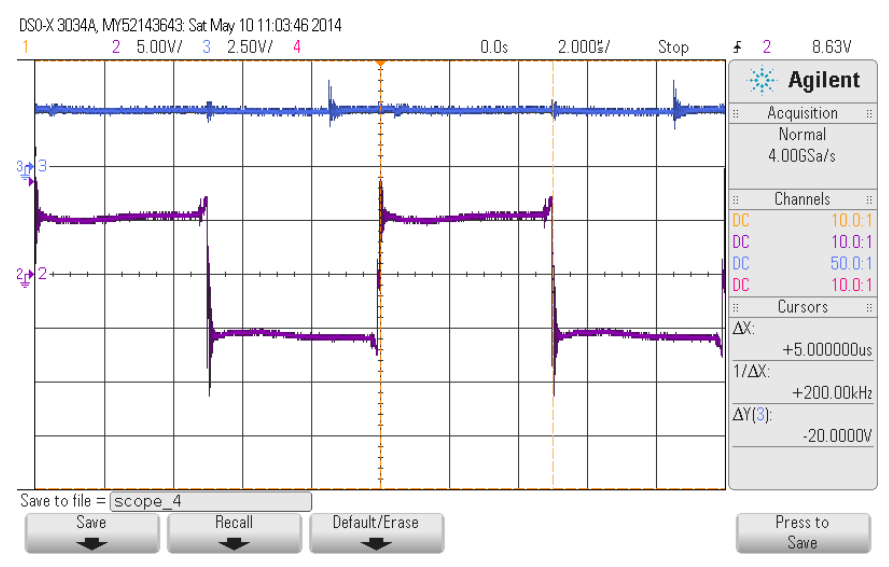

Fig. 16. The input voltage (bottom) of the primary coil and the output voltage (top) of the system at the initial point when $R_{L}=5 \Omega$.

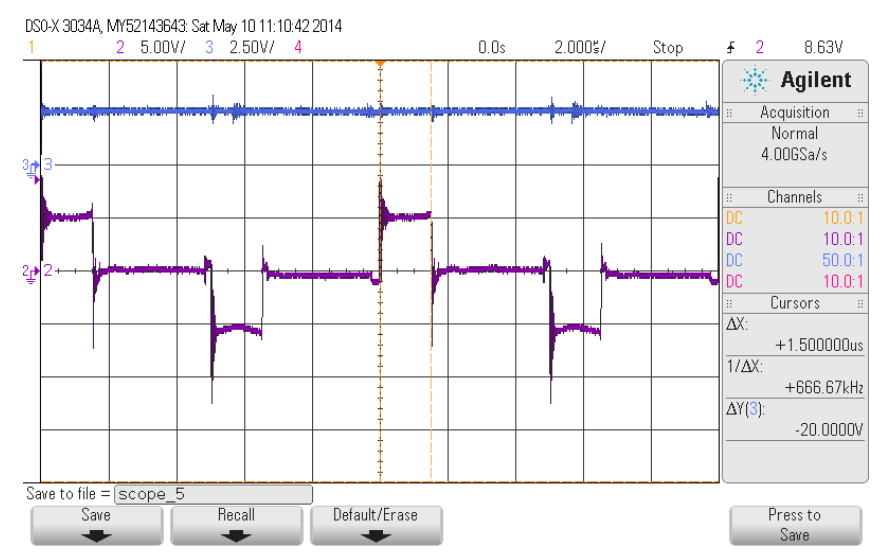

Fig. 17. The input voltage (bottom) of the primary coil and the output voltage (top) of the system at the optimum point when $R_{L}=5 \Omega$.

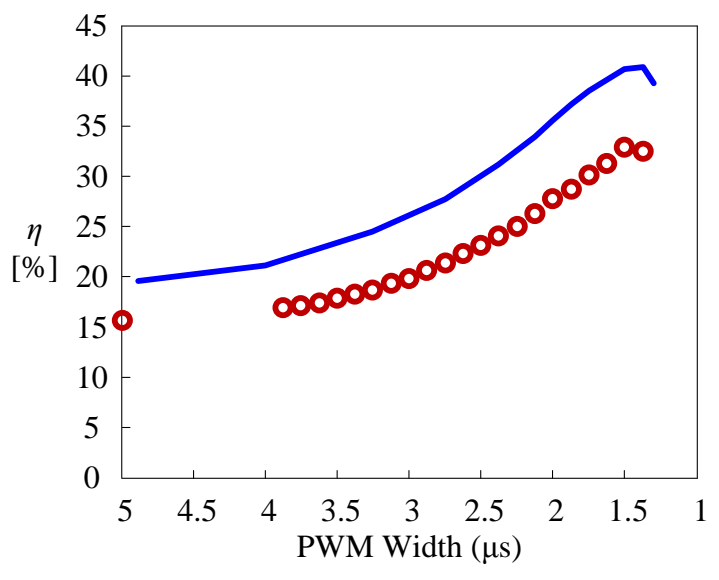

Fig. 18. Efficiency curves as a function of the pulse width of the output voltage of the inverter with $R_{L}=5 \Omega$ : top curve-simulation; bottom curve-measurement.

\section{B.Experiment with strong magnetic coupling}

Another set of measurements are obtained based on the WPT system shown in Fig. 19 in order to evaluate the performance of the proposed method for a WPT system with strong magnetic coupling. The hardware setup is similar to the previous one except that the coupling between the coils is stronger and the two coils have slightly larger self-inductance values. Therefore, the magnetic parameters of this second system are slightly different due to the shorter distance between the ferrite plates. The values of the parameters are listed in TABLE II. Since the self-inductance of the coils are slightly larger and the compensating capacitance are kept the same. Therefore, the resonant frequency of the system shifts to slightly lower than $100 \mathrm{kHz}$. In the tests, a frequency of 97.56 $\mathrm{kHz}$ is used. The load resistance of the system is $50 \Omega$ and the output voltage is designed as $15 \mathrm{~V}$. An output power of $4.5 \mathrm{~W}$ is then generated. The DC source voltage is $15 \mathrm{~V}$. Similarly, the input voltage of the primary coil is decreased gradually by adjusting the duty cycle of the inverter. The system reaches the optimum point when the pulse width of the inverter is reduced to $1.56 \mu \mathrm{s}$ as shown in Fig. 21. The variation of the input current is shown in Fig. 22. In the whole process, the output voltage is maintained at $15 \mathrm{~V}$ which is also shown in Fig. 22. The simulated and measured efficiency curves of the system are displayed in Fig.23. It can be seen that a practical energy efficiency of $65 \%$ can be achieved under strong magnetic coupling.

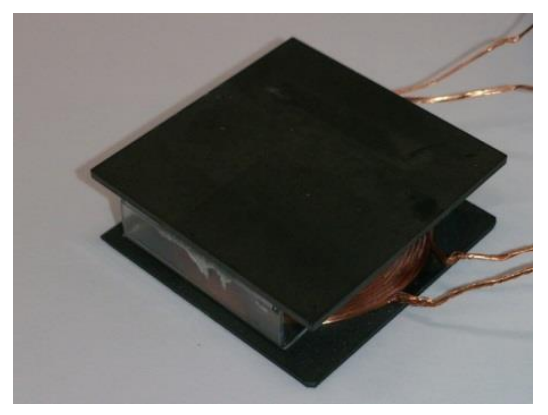

Fig. 19. A WPT system with a coupling coefficient of about 0.44 
TABLE II

PARAMETERS OF THE SYSTEM WITH A STRONGER COUPLING

\begin{tabular}{|c|c|c|}
\hline $\begin{array}{c}\text { Self-inductance of the } \\
\text { transmitter }\end{array}$ & $L_{l}$ & $25.78 \mu \mathrm{H}$ \\
\hline $\begin{array}{c}\text { Self-inductance of the } \\
\text { receiver }\end{array}$ & $L_{2}$ & $25.1 \mu \mathrm{H}$ \\
\hline $\begin{array}{c}\text { Mutual inductance } \\
\begin{array}{c}\text { Compensating capacitance of } \\
\text { the transmitter }\end{array}\end{array}$ & $M_{12}$ & $11.16 \mu \mathrm{H}$ \\
\hline $\begin{array}{c}\text { Compensating capacitance of } \\
\text { the receiver }\end{array}$ & $C_{2}$ & $105.3 \mathrm{nF}$ \\
\hline Resistance of each coil & $R_{P 1}$ and $R_{P 2}$ & $0.3 \Omega$ \\
\hline
\end{tabular}

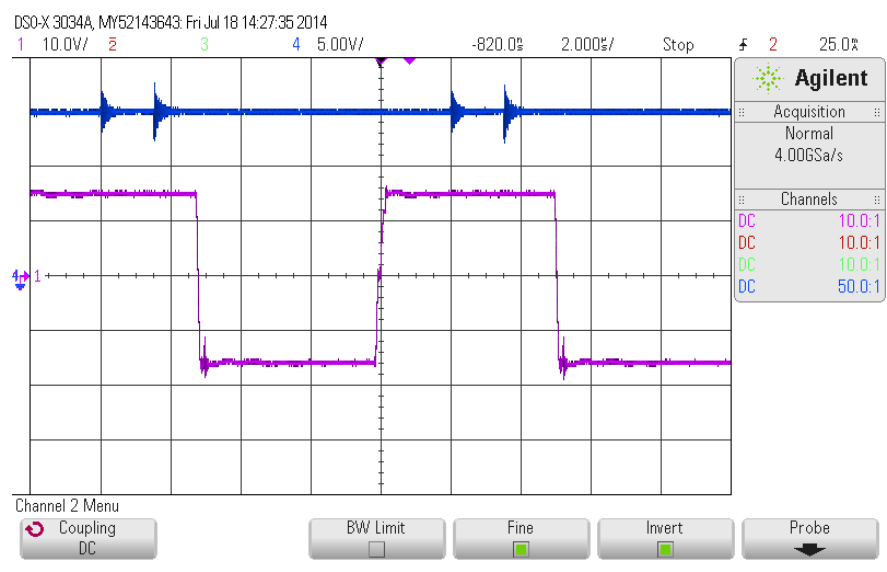

Fig. 20. The input voltage (bottom) of the primary coil and the output voltage (top) of the system at the initial point when $R_{L}=50 \Omega$.

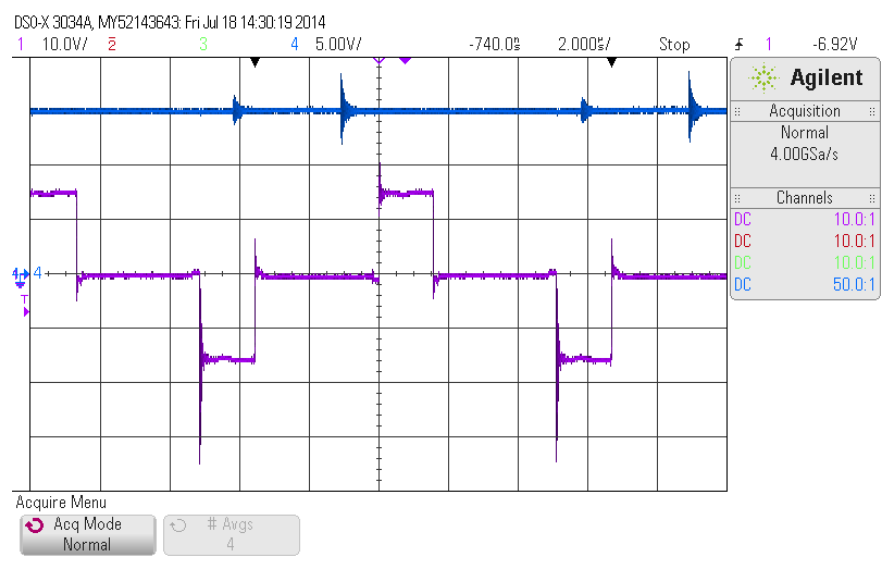

Fig. 21. The input voltage (bottom) of the primary coil and the output voltage (top) of the system at the optimum point when $R_{L}=50 \Omega$.

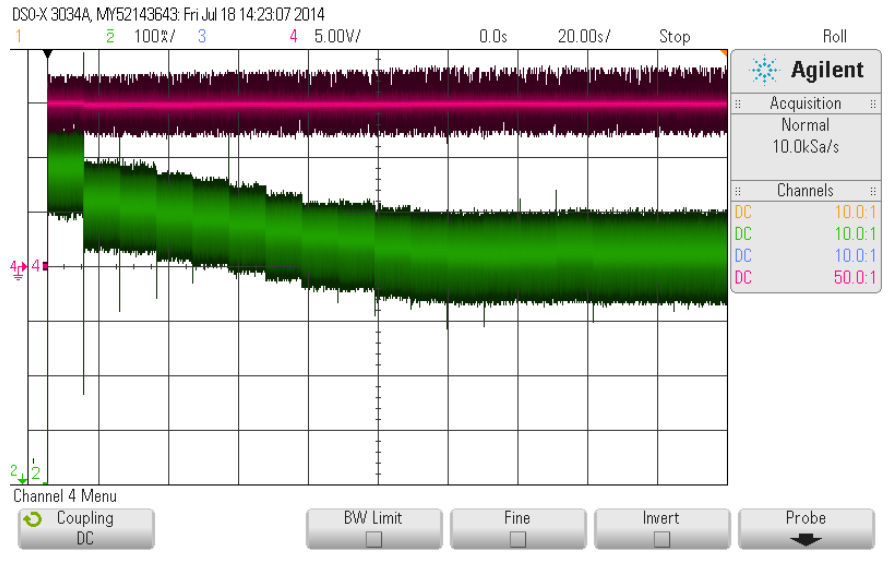

Fig. 22. The source current (bottom) and the output voltage (top) of the system.

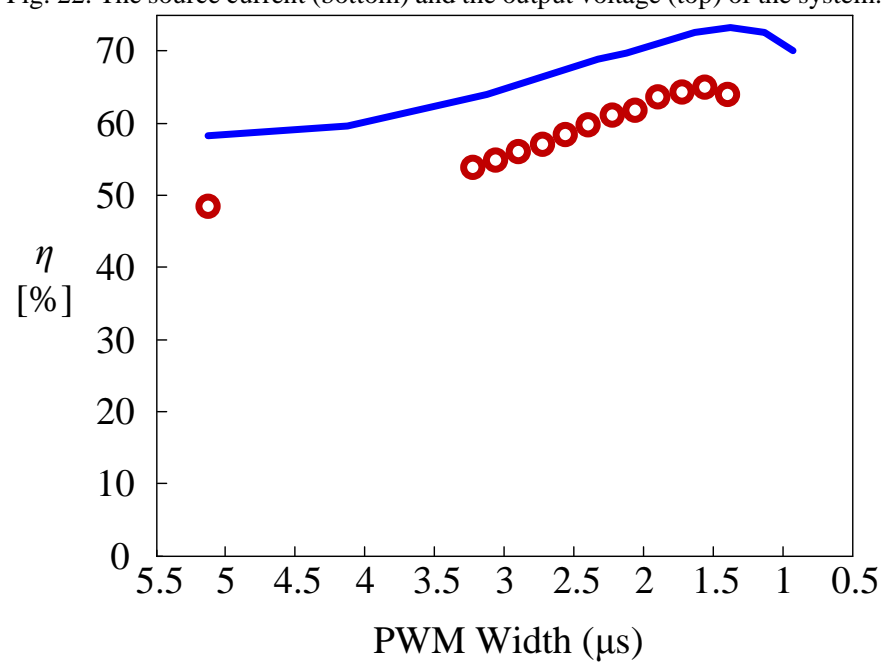

Fig. 23. Efficiency curves as a function of the pulse width of the output voltage of the inverter with $R_{L}=50 \Omega$ : top curve-simulation; bottom curve-measurement.

\section{VI.CONCLUSIONS}

A maximum energy efficiency tracking method is presented in this paper with the support of an analysis and the experimental verification of a 2-coil WPT system. The basic principle is to search for the minimum input power for any given output power. By keeping the equivalent load resistance of the receiver circuit to the optimal value through the closed-loop control of the power converter within the receiver module, maximum energy efficiency tracking can be achieved by searching for the minimum input power. Another advantage of this method is that it does not need any wireless communications between the transmitter and the receiver circuits, making it attractive in practical applications. The proposed method has been successfully tested under the situations of weak and strong magnetic coupling. Besides the differences due to the omission of the core losses and the inverter losses, the simulated and measured energy efficiency curves exhibit the same trends in both cases. 


\section{REFERENCES}

[1] A.W. Green and J.T. Boys, "10 kHz inductively coupled power transfer-concept and control," in Proc. ICPE-VSD, 1994, pp. 694-699.

[2] G.A.J. Elliott, J.T. Boys, and A.W. Green, "Magnetically coupled systems for power transfer to electric vehicles", in Proc. 1995 International Conference on Power Electronics and Drive Systems, vol. 2, 1995, pp. 797- 801 .

[3] G.A. Covic and J.T. Boys, "Modern Trends in Inductive Power Transfer for Transportation Applications," IEEE Journal of Emerging and Selected Topics in Power Electronics, vol. 1, no. 1, pp. 28-41, Mar. 2013.

[4] G.A. Covic and J.T. Boys, "Inductive Power Transfer," Proc. IEEE, vol. 101, no. 6, pp. 1276-1289, Jun. 2013.

[5] S.Y.R. Hui, "Planar Wireless Charging Technology for Portable Electronic Products and Qi," Proc. IEEE, vol. 101, no. 6, pp. 12901301, Jun. 2013.

[6] S.Y.R. Hui and W.C. Ho, "A new generation of universal contactless battery charging platform for portable Consumer Electronic equipment," IEEE Trans. Power Electron., vol.20, no. 3, pp. 620-627, May 2005.

[7] B. Choi, J. Nho, H. Cha, T. Ahn, and S. Choi, "Design and implementation of low-profile contactless battery charger using planar printed circuit board windings as energy transfer device," IEEE Trans. Ind. Electron., vol. 51, no. 1, pp. 140-147, Feb. 2004.

[8] Y. Jang and M. M. Jovanovic, "A contactless electrical energy transmission system for portable-telephone battery chargers," IEEE Trans. Ind. Electron., vol. 50, no. 3, pp. 520-527, Jun. 2003.

[9] X. Liu and S.Y.R. Hui, "Simulation Study and Experimental Verification of a Contactless Battery Charging Platform with Localized Charging Features," IEEE Trans. Power Electron., vol. 22, no. 6, pp. 2202-2210, Nov. 2007.

[10] Wireless Power Consortium, "Qi System Description: Wireless Power Transfer," Volume I: Low Power, Part 1: Interface Definition, Version 1.1, Apr. 2012.

[11] Wireless Power Consortium Website. [online] Available: http://www.wirelesspowerconsortium.com, 2014.

[12] G. Nagendra, G. Covic, and J. Boys, "Determining the physical size of inductive couplers for IPT EV systems", IEEE Journal of Emerging and Selected Topics in Power Electronics, 2014 (early access).

[13] G. Nagendra, G. Covic, and J. Boys, "Detection of EVs on IPT highways", IEEE Journal of Emerging and Selected Topics in Power Electronics, 2014 (early access).

[14] C.-B. Park, B.-S. Lee, and H.-W. Lee, "Magnetic and thermal characteristics analysis of inductive power transfer module for railway applications", in Proc. IEEE Vehicle Power and Propulsion Conference (VPPC), 2012, pp. 576-579.

[15] M. Li, Q. Che, J. Hou, W. Chen, and X, Ruan, "8-Type contactless transformer applied in railway inductive power transfer system", in Proc. IEEE Energy Conversion Congress and Exposition (ECCE), 2013, pp. 2233-2238.

[16] S. Li, and C. Mi, "Wireless Power Transfer for Electric Vehicle Applications," IEEE Journal of Emerging and Selected Topics in Power Electronics, 2014 (early access).

[17] O.C. Onar, J.M. Miller, S.L. Campbell, C. Coomer, C.P. White, and L.E. Seiber, "Oak Ridge National Laboratory Wireless Power Transfer Development for Sustainable Campus Initiative," in Proc. IEEE Transportation Electrification Conference and Expo (ITEC), 2013, pp. $1-8$.

[18] L. Sungwoo, C. Bohwan, and C.T. Rim, "Dynamics Characterization of the Inductive Power Transfer System for Online Electric Vehicles by Laplace Phasor Transform," IEEE Trans. Power Electron., vol. 28, no. 12, pp. 5902-5909, Dec. 2013.

[19] S.Y.R. Hui, W.X. Zhong, and C.K. Lee, "A critical review on recent progress of mid-range wireless power transfer," IEEE Trans. Power Electron., vol. 29, no. 9, pp. 4500-4511, Sept. 2014.

[20] C.K. Lee, W.X. Zhong, and S.Y.R. Hui, "Effects of Magnetic Coupling of Non-adjacent Resonators on Wireless Power Domino-Resonator Systems," IEEE Trans. Power Electron., vol. 27, no. 4, pp. 1905-1916, Apr. 2012.

[21] K. K. Tse, E. Johnson, B. M. T. Ho, H. S.-H. Chung, and S.Y.R. Hui, “A comparative study of maximum-power-point trackers for photovoltaic panels using switching-frequency modulation scheme", IEEE Trans. Ind. Electron., vol. 51, no. 2, pp. 410-418, Apr. 2004.
[22] K.K. Tse, M.T. Ho, H.S.H. Chung, and S.Y.R. Hui, "A novel maximum power point tracker for PV systems," IEEE Trans. Power Electron., vol. 17, no. 6, pp. 980-989, Nov. 2002.

[23] H Takanashi, Y. Sato, Y. Kaneko, S. Abe and T. Yasuda, "A large Air Gap $3 \mathrm{~kW}$ Wireless Power Transfer System for Electric Vehicles", IEEE ECCE 2012, Raleigh, North Carolina, Sept. 2014, pp: 269-274.

[24] W. Zhang, ; S.C. Wong, C.K. Tse and Q. Chen, "Design for Efficiency Optimization and Voltage Controllability of Series-Series Compensated Inductive Power Transfer Systems", IEEE Trans. on Power Electron, Vol. 29 , No. 1, 2014 , Page(s): 191- 200

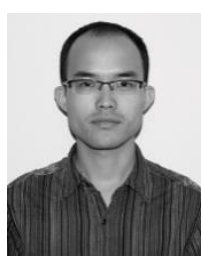

W.X. Zhong (M'13) was born in China in 1984. He received the B.S. degree in electrical engineering from Tsinghua University, Beijing, China, in 2007 and the Ph.D. degree from the City University of Hong Kong, Kowloon, Hong Kong, in 2012.

He is currently a Postdoctoral Research Fellow in the Department of Electrical and Electronic Engineering, The University of Hong Kong, Pokfulam, Hong Kong. His current research interests include wireless power transfer and power electronics.

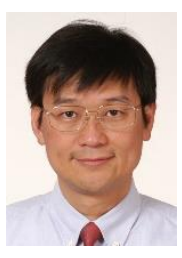

S.Y.R. Hui (M'87-SM'94-F'03) received his BSc (Eng) Hons at the University of Birmingham in 1984 and a D.I.C. and $\mathrm{PhD}$ at Imperial College London in 1987. Currently, he is the holder of the Philip Wong Wilson Wong Chair Professorship at the University of Hong Kong. Since July 2010, he has concurrently held a part-time Chair Professorship of Power Electronics at Imperial College London.

He has published over 300 technical papers, including more than 180 refereed journal publications and book chapters. Over 55 of his patents have been adopted by industry. He is an Associate Editor of the IEEE Transactions on Power Electronics and IEEE Transactions on Industrial Electronics, and an Editor of the IEEE Journal of Emerging \& Selected Topics in Power Electronics. In 2010, he received the IEEE Rudolf Chope R\&D Award from the IEEE Industrial Electronics Society and the IET Achievement Medal (The Crompton Medal). He is a Fellow of the Australian Academy of Technological Sciences \& Engineering and is the recipient of the 2015 IEEE William E. Newell Power Electronics Award. 